\title{
OS SAMBAS DO RECÔNCAVO BAIANO NO ENSINO ACADÊMICO DOVIOLÃO: UMA PROPOSTA DECOLONIAL DE ENSINO EM RESPOSTA À COLONIALIDADE DO SABER ${ }^{1}$
}

\author{
Luan Sodré de Souza ${ }^{2}$
}

\begin{abstract}
Resumo: Este artigo tem o objetivo de problematizar e apresentar algumas perspectivas para o ensino de violão no curso superior de música, principalmente quando voltado aos estudantes dos cursos de licenciatura em música, considerando os saberes e fazeres dos Sambas do Recôncavo Baiano enquanto uma referência epistêmica. A partir de um olhar mais atento para as Epistemologias do Sul (SOUSA; MENESES, 2009), e da perspectiva do giro decolonial, embasado pelas ideias de Walter Mignolo, Enrique Dussel, Anibal Quijano, centralizando a discussão no pensamento de fronteira, defendido por Grosfoguel (2009), pretendo discutir caminhos de visibilização de saberes e fazeres que são colocados em posição subalterna por conta de uma estrutura colonial que impera nas estruturas da sociedade brasileira. Dessa maneira, este trabalho busca refletir sobre caminhos de trânsito entre aulas coletivas de violão na graduação em música e os saberes e fazeres dos Sambas do Recôncavo Baiano. Para tal, parto da tese de que é possível construir uma proposta de ensino fronteiriça, buscando propor caminhos de trânsito epistemológico a partir da compreensão dos fundamentos destes dois campos de formação - o samba de roda e o ensino de violão na Universidade Federal da Bahia. Aqui, trarei algumas reflexões que podem contribuir para o ensino de instrumentos musicais na atualidade. Além disso, pretendo apontar perspectivas para um ensino de instrumentos musicais sem preconceitos, respeitoso com as tradições brasileiras, igualitário e que represente o Brasil, considerando a sua dimensão e riqueza cultural e epistêmica.
\end{abstract}

Palavras-chave: Ensino de violão. Decolonialidade. Educação musical.

\footnotetext{
${ }^{1}$ Este texto é baseado em uma pesquisa de doutorado em andamento orientada pela Profa. Dra. Cristina Tourinho e que vem sendo apoiada pela Coordenação de Aperfeiçoamento de Pessoal de Nível Superior Brasil (CAPES) - Código de Financiamento 001.

${ }^{2}$ Licenciado em Música, Mestre e Doutorando em Educação Musical pelo Programa de Pós-Graduação em Música da Universidade Federal da Bahia. É professor da Universidade Estadual de Feira de Santana, lotado no Departamento de Letras e Artes - DLA, onde atua no curso de Licenciatura em Música.
} 


\section{LOS SAMBAS DE RODA DEL RECÔNCAVO DE LA BAHÍA EN LA ENSEÑANZA COLECTIVA DE LA GUITARRA EN LA UNIVERSIDAD: UNA PROPUESTA DECOLONIAL DE ENSEÑANZA EN RESPUESTA A LA COLONIALIDAD DEL SABER}

Resumen: El presente trabajo tiene el objetivo de problematizar y presentar algunas perspectivas para la enseñanza de la guitarra en el curso superior de música, principalmente cuando se dirige a los estudiantes de los cursos de profesorado. A partir de una mirada más atenta a las Epistemologías del Sur (SOUSA; MENESES, 2009), y de la perspectiva del giro decolonial, basado en las ideas de Walter Mignolo, Enrique Dussel, Anibal Quijano, centralizando la discusión en el pensamiento de frontera, Grosfoguel (2009), pretendo discutir caminos de visibilización de saberes y haceres que son colocados en posición subalterna por cuenta de una estructura colonial que impera en las estructuras de la sociedad brasileña. A partir de esa reflexión, tengo el objetivo de buscar caminos de tránsito entre clases colectivas de guitarra en la graduación en música y los saberes y haceres de los Sambas del Recôncavo Baiano. En el marco de la creencia en la tesis de que es posible construir una propuesta de enseñanza fronteriza, buscando proponer caminos de tránsito epistemológico a partir de la comprensión de los fundamentos de estos dos campos de formación, el "samba de roda” y la enseñanza de guitarra en la Universidad. Sin embargo, traer algunas reflexiones que pueden contribuir con la reflexión sobre la enseñanza de instrumentos musicales en la actualidad. Además, pretendo apuntar perspectivas para la enseñanza de instrumentos musicales en un futuro deseado, sin prejuicios, de respeto, igualitario y que represente el Brasil, considerando su dimensión y riqueza cultural.

Palabras-clave: Enseñanza de la guitarra. Decolonialidad. Educación musical.

\section{Chamada $^{3}$}

Antes de aquecer os pandeiros, afinar as cordas da viola e do violão para sambar na roda que se materializa neste texto, peço licença para apresentar a roda na qual as discussões irão sambar. Apresento a roda, a paisagem, o contexto no qual este trabalho está inserido, a fim de contextualizar, informar, esclarecer e tentar construir bases para o entendimento das discussões que "receberão suas umbigadas" para entrar na

\footnotetext{
${ }^{3}$ Chamada é o termo utilizado para nomear o momento em que a viola faz um toque iniciando o ritual do Samba Chula. É como se chamasse todos para aquele rito.
} 
"roda" no decorrer deste artigo. Os primeiros a "brincar" serão os Sambas do Recôncavo Baiano, para que este trabalho de ensino musical comece com música e com seres humanos e, em seguida será a vez do ensino acadêmico do violão. Continuando a "ritualidade", acreditando que as leitoras e os leitores já tenham informações contextuais suficientes, apresentarei a ideia de uma proposta de ensino decolonial, norteada por um pensamento crítico de fronteira - onde o conhecimento é construído a partir do encontro de diferentes referências epistêmicas, constituído a partir da inserção dos saberes e fazeres dos Sambas do Recôncavo Baiano nas aulas coletivas de violão na graduação em música. Também buscarei, ao longo do texto, conduzir os leitores e leitoras para os principais focos deste trabalho que são: propor bases para trânsitos epistemológico teórico-práticos, no contexto do ensino de violão na academia, a fim de contribuir na formação musical dos professores de música; oportunizar o contato com uma outra epistemologia musical de maneira prática, se comprometendo com uma iniciativa decolonial teórico-prático-epistemológica para o ensino coletivo de violão na graduação como um ato político.

\section{A roda: os sambas do recôncavo baiano}

Os Sambas do Recôncavo Baiano constituem uma tradição musical, poética e coreográfica brasileira. Como esta tradição está presente em várias cidades da macrorregião do Recôncavo Baiano, ela acaba ganhando características diferentes a depender da sua localidade. Tais características geram uma variedade de formas, ritualidades, ritmos, instrumentações, cantos, danças, criando variantes como Samba Chula, Samba Barravento, Samba corrido, Samba amarrado, Samba de viola, Samba de beira de praia, como destaca Katharina Döring (2016a, p. 76-78):

O samba de roda [...] não se restringe aos centros urbanos e mostra sua vivacidade em várias regiões, que em boa parte é pouco conhecido pelos estudiosos da cultura e música afro-brasileira. Termos como samba de coco, samba rural, samba de caboclo, samba de estivador, samba duro, samba de parada, samba batuque, samba martelo, samba tropeiro, samba-de-rojão, samba beiramar, samba litoral, samba catingueiro, samba de verso, samba de metro, samba no pé, samba de "esparro", samba de "putaria", samba de "ma-tratá" e chula-e-batuque, além dos citados samba corrido, samba amarrado, samba chula, samba de viola, samba de barravento e samba de 
parelha, revelam a riqueza deste estilo genericamente denominado samba de roda (DÖRING, 2016a, p. 76-78).

Após o reconhecimento como Patrimônio Cultural do Brasil em 2004 e a proclamação como Obra Prima do Patrimônio Oral e Imaterial da Humanidade pela UNESCO em 2005, ampliou-se o interesse acadêmico sobre essa manifestação. Importante salientar que antes da patrimonialização já haviam pesquisadores engajados com essa tradição trabalhando, publicando textos, produzindo material audiovisual. Mas, é notório que após a outorga do título tem sido crescente a quantidade de trabalhos ligados a este tema, apenas para citar alguns que tive acesso até a redação deste texto ${ }^{4}$, dentre os diversos trabalhos que vêm sendo produzido sobre esta tradição: Sandroni (2005, 2006, 2007, 2010); Sandroni \& Sant'anna (2007); Nobre (2008, 2017); Mendes \& Júnior (2008); Carmo (2009); Lordelo (2009); Mesquita Costa (2012); Barreto, Rosário, Gumes (2015)5; Graeff (2015); DÖRING (2016a, 2016b); Exdell (2017). Essa visibilização político-cultural-acadêmica tem contribuído para que as epistemologias ligadas aos Sambas do Recôncavo conquistem vozes em contextos que vão além do campo da etnomusicologia e antropologia, como no campo da economia, da produção cultural, educação, bem como, da educação musical, que historicamente tem sido pautada sobre epistemologias hegemônicas, principalmente ligadas as tradições musicais difundidas no norte global e social, epistemologias que ocupam o outro lado da linha abissal, quando analisadas sobre a influência das concepções de Boaventura Sousa Santos (2007, 2009). A linha abissal é uma fronteira invisível que separa o norte e sul global para além da visão geográfica, pautando-se principalmente nas invisibilizações e violências de todas as ordens, uma linha que reafirma e evidencia as dominações econômicas, políticas e culturais, fomentada por um dos lados da linha a fim de dar manutenção a hierarquização dos saberes e a negação da diversidade.

\footnotetext{
${ }^{4}$ Apesar de reconhecer a grande importância da produção de outros pesquisadores sobre este tema, não foi possível e também não era a intensão deste texto ter uma lista que incluísse todas as produções neste campo. No entanto, acho fundamental destacar as produções de três autores que têm se debruçado sobre os Sambas do Recôncavo cujo suas obras não foram incluídas no corpo do texto, a saber: Prof. Dr. Francisca Marques, Prof. Dr. Michael lyanaga e Prof. Dr. Ari Lima.

${ }^{5}$ Embora Luciana Barreto, Rosildo do Rosário e Scheilla Gumes sejam os organizadores desta obra, a pesquisa e produção dos textos é creditada a Profa. Dra. Katharina Doring, que tem grande produção ligada aos Sambas do Recôncavo Baiano, desde de 2002 publicando diversos trabalhos sobre o tema.
} 
No que tange aos Sambas do Recôncavo, a depender da variante em questão, as regras dos rituais podem ser rígidas, mas, ao mesmo tempo, podem manter liberdade dentro dos seus parâmetros para o improviso. Os termos musicais utilizados são específicos, exigindo alguma aproximação para se inteirar de determinados conceitos. Não mudam apenas as terminologias, mas a concepção dos elementos musicais do samba. Sobre este tema, alguns autores já atentaram para as ressignificações constituídas no âmbito dos conceitos musicais no contexto dos Sambas do Recôncavo Baiano, o que abriu um campo conceitual onde emergiu tanto a ideia de "teorias nativas", defendida por Tiago de Oliveira Pinto (2001) quanto a ideia de "teoria musical popular", defendida por Ralph Waddey (2006). Tiago de Oliveira Pinto (2001) explica que:

\begin{abstract}
Nenhuma forma de cultura expressiva exige, mesmo no discurso entre leigos, tão vasto "vocabulário técnico" como a música: além do termo música, fala-se no Brasil naturalmente de ritmo, tonalidade, melodia, cantiga, instrumento, e mesmo de harmonia, compasso, cadência, escala, sonoridade, timbre etc. Diferente de outras áreas do saber local, não é contraditório teorias nativas operarem no campo musical com concepções próprias, não-ocidentais, e utilizarem, ao mesmo tempo, esta terminologia, que é derivada da teoria musical europeia. Quando, no entanto, músicos, mestres e entendidos de manifestações de tradição local utilizam termos desta natureza, deparamos com uma ressignificação própria e precisa da terminologia, dentro de um corpo definido de saber (PINTO, 2001, p. 245).
\end{abstract}

Dessa forma, os conceitos definidos pelas convenções estéticas da música de origem ocidental europeia ligada as tradições sacras ou de concerto, a citar: harmonia, ritmo, melodia, repertório, timbre, cadência, tonalidade, toques, alterações - sustenido e bemol, técnicas de execução e afinação, são reelaborados, ressignificados. Essa "teoria nativa" ou "teoria musical popular" utiliza-se apenas dos termos linguísticos, do léxico ligado a teoria musical ocidental europeia, que é ressignificado, passando a representar novas semânticas. Por exemplo, a ideia de tonalidade mais difundida no campo musical, ligada a já citada teoria da música ocidental europeia, parte da identificação de uma tônica - nota fundamental que dá nome a tonalidade - e suas relações harmônicas, já no contexto dos sambas que utilizam a viola machete a tonalidade ganha um outro significado. Neste caso, a música da "violinha" baseia-se na noção de cinco tons distintos: ré 
maior, dó maior, lá maior, sol maior e mi maior. Além da ideia de altura, esta outra semântica da tonalidade também agrega a posição ao longo da regra (braço) da viola onde o acorde será formado.

\begin{abstract}
"Ré maior grande" compõe-se apenas nas quatro ordens mais graves e toca-se usando um padrão que percorre a quarta e a quinta ordens. "Ré maior pequeno", [...] é talvez o mais comum de todos os "tons" da viola para samba. "Ré maior sustenido" não é um acorde maior com a fundamental de Ré sustenido, como seria na teoria musical convencional europeia. É, sim, um acorde cuja fundamental é Ré, mas formado numa posição mais adiante na regra da viola; vale dizer, o acorde soa mais agudo. O violeiro diria que este acorde é "mais embaixo", referência à maneira como o instrumento é empunhado: os sons mais agudos da viola encontram-se mais perto do chão (em termos espaciais, mais baixos), da mesma forma como foram representados em alguns sistemas renascentistas de tablatura para o alaúde. "Ré maior sustenido bemol" é Ré maior numa quarta posição, ainda mais aguda, ou seja "mais embaixo". O "Sustenido de Lá maior" é conhecido por um nome especial, "samango", palavra de provável origem banto, que significa "preguiçoso" ou "indolente" (WADDEY, 2006, p. 115).
\end{abstract}

Além da ressignificação dos termos, o uso das tonalidades no samba de roda está ligado a pressupostos que vão além da ideia das alturas. No caso do machete, a concepção responsável pela produção sonora está fundamentada em um pensamento acústico-mocional em que padrões são definidos por sequências de movimento, técnicas específicas, configurações rítmicas, relação de acento e harmonia. Os padrões de cada "tom de machete" carrega características que irão repercutir na música e, inclusive, na escolha do "tom" na hora de sua execução no conjunto. A ré maior é considerada a melhor para o acompanhamento de um samba puxado pelo cantor de forma "solta" e "esparramada" e também é usado para dar fluência à festa, segurança e velocidade nos pés dos sambadores e sambadeiras, além de uma base favorável às chulas improvisadas e respondidas. O mi maior é considerado o mais "pesado" e "duro" dos tons, é bastante utilizado para colocar à prova um puxador de chula recém-chegado à festa (PINTO, 2001). Ainda no que se refere ao termo tonalidade, existem outros usos que são possíveis de serem identificados no contexto da cultura popular e, consequentemente, do samba de roda, como o uso para se referir a uma mudança de caráter na música, 
como no berimbau dentro do contexto da capoeira, ou, ainda, ligado a uma mudança timbrística, como na troca de registros de uma sanfona.

Outro aspecto inerente à teoria musical nativa dos violeiros e sambadores do Recôncavo baiano é o conceito de toque. Segundo Tiago de Oliveira Pinto (2001), os toques seriam frases melódicas compostas de estruturas rítmicas marcadamente africanas e é um elemento identitário do samba de roda. Os toques são executados quando a viola para de fazer o acompanhamento rítmico-melódico-harmônico das partes cantadas e se destaca do resto do grupo instrumental, fazendo uma espécie de "solo", "chamando" a sambadeira para percorrer, brincar e dançar dentro da roda. O Mestre e violeiro Milton Primo, em entrevista uma entrevista em novembro de 2008, chamou esses momentos da viola de "passagens". Em uma tentativa de estabelecer uma relação, de criar pontes com os conceitos ligados a música de tradição ocidental europeia de concerto, com o objetivo de construir um caminho didático para um melhor entendimento daqueles que não convivem com os contextos dos Sambas do Recôncavo Baiano, diria que estes toques se estabelecem sobre uma base tonal, quase sempre de relação tônicadominante. A performance da viola ou do instrumento que a substitui cavaquinho, violão, guitarra - é construída a partir do revezamento de padrões rítmicos-melódicos com caráter de acompanhamento, lembrando ostinatos, nos momentos em que há canto e, momentos onde a viola está mais livre para fazer os seus toques, sem o compromisso de acompanhar um canto, mas empenhada em brincar com a sambadeira que está na roda.

Quanto à instrumentação, embora exista um movimento de resgate da viola machete como uma das ações ligadas a salvaguarda desta tradição, a depender da região do recôncavo, ela varia. Dessa maneira, tenho acreditado que mais importante do que as variantes timbrísticas, são as maneiras como uma simples batida de palmas, um toque de uma faca em um prato ou uma batida de lata podem conduzir a experiência acústico-cênico-espiritual da roda de samba. A referência de altura é tradicionalmente estabelecida pelo toque das violas, embora, nos dias atuais, o cavaquinho, o violão e a guitarra também tenham ocupado este espaço. A instrumentação, a variante timbrística, é importante. Em alguns grupos, os mais tradicionais, é fundamental que o samba seja tocado por determinados instrumentos, sob o argumento do risco de descaracterização do samba. Alguns, irão inclusive ser inflexíveis quanto a ordem em que os instrumentos devem estar dispostos na 
roda. No entanto, mesmo respeitando os saberes dos mestres, dos autores e todos aqueles que pensam diferente, concordo com Emília Biancardi (2000), quando diz que os sambas podem ser tocados de diversas maneiras, dando vida a roda

[...] com pandeiros, com violas, com violões, com sanfonas, com berimbaus, com atabaques, com cavaquinho, com banjo, com chocalhos e com reco-reco. Ou simultaneamente com todos esses instrumentos. E também com instrumentos improvisados: duas colheres de sopa, percutidas na palma da mão, lata vazia, prato de mesa raspado com uma faca, pente de cabelo envolto em papel de seda ou um simples palmeado (BIANCARDI, 2000, p. 277).

O canto, quase sempre conduzido por uma autoridade na tradição, reflete muito mais do que suas técnicas específicas e seus sistemas musicais peculiares $^{6}$, muitas vezes expressa a alegria, a dor, a "lavagem de roupa suja", a disputa e a convivência, o respeito e o desrespeito, as devoções, as recordações, as obrigações, a vida cotidiana de uma maneira geral, segundo Döring:

O samba representa uma categoria maior que pode estar relacionada com muitos aspectos da vida, com momentos profundos, ritos de passagem, pedidos e saudades, com a festa da vida, mas também com o seu complemento, a morte. Muito comuns são os relatos da relação entre samba, chula e o trabalho, como vemos ainda pelos depoimentos de Mestre Nelito, Domingos Preto, Mestre Quadrado, Dona Zelita e Paião, que se lembrou de um samba antigo que fala do trabalho da roça: |. Eu plantei na baixa, meu feijão de moita - A maré encheu, samba minha roxa! : 1 Com este canto fazendo a ponte para o canto da chula, o blues do engenho de açúcar que traz a memória do 'penar' (2016, p. 92).

A roda de samba é o lugar onde o sambador conecta a sua vida cotidiana à sua ancestralidade e constrói o futuro fazendo o presente. Um

\footnotetext{
${ }^{6}$ Habituado a certas relações de intervalos, principalmente também às afinações diatônicas e temperadas da música ocidental, o nosso ouvido pode, automaticamente, "corrigir" determinadas "desafinações" alheias. Estar "fora do tom" ou "desafinado", em si já são conceitos eurocêntricos, pois pressupõem que o outro esteja errado pelo fato de estar fora das normas do mundo musical próprio, este sim, supostamente "no tom" e "afinado" (PINTO, 2001, p. 242).
} 
espaço sagrado onde os versos poetizam a memoria, a dor, as alegrias e, sobretudo, a vida.

Para falar um pouco sobre a rítmica desta tradição, bem como do seu fenômeno acústico em geral, irei me apropriar de alguns conceitos desenvolvidos por Gerard Kubik (1979), Nketia (1974), bem como, de conceitos ligados a teoria da música ocidental europeia. O ritmo nos Sambas do Recôncavo Baiano é quase sempre estruturado a partir de uma sequência cíclica de 16 unidades de tempos mínimos, que irão gerar ciclos formais. Ou seja, são intervalos de tempo, com uma duração de 16 unidades de pulsações mínimas, que irão se repetir como um loop, como um ritornello constante. Esses intervalos de tempo são onde, por meio do som, da prolongação do som e/ou do silêncio, do ataque e da ausência de ataque, serão construídos os padrões rítmicos que darão forma acústica ao samba de roda. Pulsação mínima ou pulsação elementar é a presença contínua de unidades de tempos mínimos, contidos na menor distância temporal entre estes. Pode apresentarse acusticamente através de sons, de pausas, ou apenas como o pensamento que estrutura a música, como podemos ver no exemplo abaixo, no qual temos 16 unidades de tempo entre dois ritornellos. Muitas vezes estas pulsações mínimas estão presentes na dança das sambadeiras, no chamado "miudinho", que é uma maneira de dançar em que os pés marcam as 16 pulsações em um movimento alternado de arrastar os pés no chão, se deslocando pela roda. Segundo a sambadeira, capoeirista e professora Natureza França em uma oficina com as sambadeiras do grupo "Voa Voa Maria", este movimento é como se estivéssemos em cima de um pano de chão e começássemos a secar o chão sem tirar os pés de cima do pano.

Exemplo: $16^{8} \|: \ldots \ldots \ldots \ldots \ldots$. $\|$

Outro conceito importante é o de marcação, também conhecido como beat e off-beat. Neste momento não me refiro a marcação atribuída ao violão, que seria as melodias graves executadas por este instrumento que tem a função de conduzir, acompanhar, marcar o samba. Me refiro à materialização do som e da pausa ao longo dos ciclos formais de 16 pulsações

\footnotetext{
${ }^{7}$ Ritornello é um sinal de repetição oriundo da notação musical tradicional europeia, formado por uma barra dupla seguida de 2 pontos, quando no início de um trecho musical ( ||: ) ou dois pontos seguidos de uma barra dupla, quando no final de um trecho musical ( : | | ). Este sinal gráfico significa que o trecho entre os ritornellos devem ser repetidos.

${ }^{8}$ Número de pulsações elementares.
} 
elementares. Durante a execução musical, as resultantes das marcações, do ataque, do som, da prolongação do som, da ausência de ataque ou das pausas geram padrões sonoros que irão compor o fenômeno acústico do samba de roda. É possível que estes padrões, durante as suas repetições ganhem variações, no entanto, todas elas devem estar de acordo com a linha-guia.

As linhas-guias, patterns, timelines, claves, dentre outros nomes possíveis, são padrões estruturantes. Essas linhas-guias funcionam como "chaves" da música, que podem estar soando, materializados por alguma fonte sonora ou apenas constar como referencial norteador para execução dos outros padrões. Estes padrões quase sempre são executados pelas palmas, tabuinhas e tamborins, quando estes instrumentos compõem a instrumentação. Existem duas linhas guias que são mais comuns no contexto do samba de roda do Recôncavo da Bahia, as quais seguem nos exemplos abaixo, onde o (x) significa o ataque, o som, e os pontos (.) significam pausas ou prolongamento do ataque anterior.

Exemplo: $16\|: \mathrm{x} \ldots \mathrm{x} \ldots \mathrm{x} . \mathrm{x} \ldots \mathrm{x} \ldots \mathrm{x} .:\|^{9}$

Exemplo: $16\|: \mathrm{x} . \mathrm{x} \ldots \mathrm{x} \ldots \mathrm{x} \ldots \mathrm{x} . \mathrm{x} \ldots\|^{10}$

Outro ponto importante de ser destacado é a relação que pode ser estabelecida entre a ritualidade do samba de roda - incluindo as diversas nuances existentes numa roda - com a vida cotidiana, materializando na brincadeira séria, de forma poético-artístico-metafórica, diversos aspectos da vida humana. Flávia Candusso (2009), em sua tese sobre educação musical na capoeira $^{11}$, dentre outros assuntos, discute um aspecto semelhante: as relações entre a pequena roda e a grande roda. A pequena roda representa a roda de capoeira e a grande representa o mundo. Essa leitura também é possível de ser feita no samba de roda, o que mostra que os saberes e fazeres da tradição estão diretamente ligados a visão de mundo dos seus participantes, que é traduzida de forma artística.

\footnotetext{
${ }^{9}$ Esta linha-guia é comum no Samba Chula, como pude observar nas regiões de Santo Amaro, São Francisco do Conde, Terra Nova. É possível que o samba chula de outras regiões sigam outras linhas-guia, no entanto, nessa pesquisa, eu não tive acesso a essa informação.

${ }^{10}$ Esta linha-guia é mais comum no samba corrido, no samba duro, no samba de beira de praia, entre outros, como pude observar nas regiões de Cachoeira, Salvador, Matarandiba.

${ }^{11}$ A capoeira é uma tradição brasileira de matriz africana que materializa as suas crenças e visão de mundo através de um jogo de corpo em uma roda embalada por cantigas, geralmente acompanhadas por palmas, pandeiros, berimbau, caxixi, agogô, reco-reco e atabaque.
} 
Quando a questão é: como aprenderam os seus saberes e fazeres? É quase unânime a resposta de que aprenderam sozinhos por meio da observação, escuta, da imitação, do fazer, da prática, da memorização, como diz Dona Bete, "não tenho nada escrito por papel, tá tudo na cabeça!" (BARRETO; ROSÁRIO; GUMES, 2015, p. 29), o que se reforça com a vivência e a convivência com os mestres. A música está nas pessoas, podendo ser acessada a qualquer momento. Ainda pensando na dimensão sagrada que está presente na relação dos participantes com esta tradição, acredito que a maneira como a música é transmitida, entendida, produzida, compartilhada e experienciada têm influência direta no tipo de relacionamento que é construído, bem como na dimensão sagrada que se institui.

Até este ponto, falamos sobre o samba de roda enquanto tradição musical afro-brasileira geograficamente situada, da sua patrimonialização, da relação com a sociedade. No que tange ao fenômeno acústico, foi destacada a ressignificação dos conceitos musicais no contexto dos Sambas do Recôncavo, a sua instrumentação, sua poética, seus toques, bem como a sua rítmica. Em relação ao caráter humano, foi possível refletir um pouco sobre o sentimento de pertencimento dos participantes e de como se dá essa construção.

Esse pequeno panorama permite inferir que existem maneiras de pensar, se relacionar, conceber, entender e fazer música no contexto dos Sambas do Recôncavo Baiano que são diferentes de como concebemos a música no âmbito acadêmico brasileiro, falando de maneira geral e entendendo que a maioria dos cursos de música em universidades públicas brasileiras têm bases epistemológicas ligadas a música tradicional europeia de concerto. Dessa forma, estas outras maneiras de pensar a música, outros valores ou outras aprendizagens musicais faz com que possamos construir uma consciência da existência de outros mundos musicais. Foi possível notar que mesmo utilizando conceitos que caberiam nos moldes coloniais de entendimentos sobre a música como tonalidade, ritmo, canto, a maneira como eles são entendidos e articulados nos leva a outras concepções e reafirmam a possibilidade de múltiplas compreensões sobre estes conceitos, bem como sobre o fazer musical. Este fato também nos conduz a refletir sobre outras lógicas para se pensar a música e a Educação Musical. É importante salientar, desde já que, de forma alguma, esse texto celebra uma ruptura com os padrões, concepções e entendimentos ligados a música tradicional europeia, pelo contrário, reconhece a sua importância, inclusive na formação 
das tradições ligadas a cultura popular brasileira. No entanto, busca a inclusão de outras referências epistemológicas historicamente invisibilizadas. A ideia de um pensamento decolonial não é uma nova hegemonia com um projeto opressor diferente, pelo contrário, é a tentativa de uma negociação transcultural, que inclui, que quebra as hierarquizações, que constrói através do diálogo, do encontro, que habita a fronteira dos conhecimentos.

Segundo Pedro Abib "existe uma outra lógica reinante no universo da cultura popular, responsável por formas diferenciadas de se relacionar com o sagrado e o profano, o tempo e o espaço, os saberes e a natureza" (2004, p. 57). Essa lógica foge das categorias de análise hegemônicas, quase sempre ligadas a um projeto de sistema-mundo euro-norte-americano moderno, capitalista, branco, cristão, patriarcal, colonial, baseados na temporalidade linear, na verificação analítica, em uma racionalidade cartesiana.

Nos últimos anos, algumas pesquisas têm contribuído como referências importantes para elucidar outras lógicas de se conceber os conhecimentos/saberes no ensino de música afro-brasileira. Pedro Abib $(2004,2005)$ reflete sobre a lógica diferenciada da cultura popular destacando a memória, a oralidade, a ritualidade, a temporalidade não-linear, e a roda como fundamentos estruturantes das tradições ligadas a cultura popular. Flavia Candusso (2009), por sua vez, reflete sobre educação musical e capoeira angola, articulando alguns aspectos com o que ela chama de valores civilizatórios afro-brasileiros, são eles: circularidade, musicalidade, ludicidade, corporeidade, cooperativismo/comunitarismo, oralidade, memória, ancestralidade, religiosidade e energia vital (Axé). Guilherme Bertissolo (2013), em sua tese sobre composição e capoeira, reflete sobre as dinâmicas do compor entre música e movimento e destaca quatro aspectos: ciclicidade, incisividade, circularidade, surpreendibilidade.

Consciente da profundidade epistemológica que orienta os Sambas do Recôncavo Baiano, me pergunto se é possível construir conhecimentos a partir do encontro das turmas de violão na graduação em música e esses saberes ligados a essa tradição, levando em consideração a lógica, a racionalidade, a cosmovisão, os saberes localizados, bem como as diretrizes que orientam esta disciplina, assim como a sua função no currículo dos cursos. Mas, para adentrar esta questão e desenvolver este pensamento é preciso entender um pouco sobre o ensino de violão na graduação em música. 


\section{A roda: o ensino acadêmico do violão}

O ensino de violão, enquanto componente curricular, está presente, de alguma forma, em grande parte dos cursos superiores de música no Brasil. Há pelo menos duas possibilidades: componentes ligados a cursos de bacharelado no instrumento, onde o ensino do violão torna-se o foco principal do curso; e componentes no qual o ensino de violão tem o objetivo, além da aprendizagem do instrumento, de contribuir ou dar suporte para outras atividades dos cursos. Esses casos integram as matrizes curriculares de cursos de licenciatura, de composição, entre outras formações. Em ambas as possibilidades, existe uma variedade de caminhos metodológicos e de conteúdos para conduzir o ensino de violão para essas turmas, e essas aulas ainda podem ser presenciais ou à distância, individuais ou coletivas. Sobre formatos e estratégias de aulas de violão em cursos superiores de música, há diversos trabalhos que trazem este tema, como: Moura (2008), Matos (2009), Zorzal (2010), Pereira (2012), Braga \& Tourinho (2013), Souza (2015), Westermann (2017), que tratam tanto de aulas no bacharelado em violão quanto de componentes ligados a outros cursos de música, como as licenciaturas.

O ensino do violão nas universidades brasileiras tem grande influência da música ocidental europeia de concerto. Essa influência tem sido importantíssima para a criação de uma cultura do violão de concerto no Brasil e, pela construção do que Carlos Galileia (2012), no seu livro Violão Ibério chamou de "violão solo, de caráter popular", vertente onde posso destacar, dentre outras, as obras de Dilermando Reis, Garoto e João Pernambuco. Sem dúvidas, as influências do chamado "violão clássico", que se apresenta como uma das grandes escolas do violão e detentora de uma sistematização de uma técnica de tocar o instrumento, tem contribuído de maneira excepcional para a cultura violonística brasileira. Não poderia afirmar que essa seria a única referência, visto que tem cursos que buscam incluir outras maneiras de pensar o violão, como é possível ser visto no trabalho de Robson Barreto Matos (2009), que propõe o ensino da técnica violonística através do choro brasileiro e também o de Marcelo Mateus Oliveira (2015), que propõe a improvisação musical como ferramenta pedagógica no ensino do violão. Mas ainda assim, o violão de concerto europeu é colocado numa posição onde 
ocupa um lugar epistemologicamente hegemônico nas universidades. O que se coloca em discussão neste texto não é a importância da música europeia para o ensino de violão, e sim o seu posto de referência epistemológica hegemônica, seu centrismo, para se pensar o ensino de violão no contexto acadêmico. No Brasil, temos influências de diversas outras matrizes musicais, como a africana e a indígena, que são colocadas em posição subalterna, quando não são totalmente descartadas. Pudemos ver que os Sambas do Recôncavo Baiano têm referências epistêmicas próprias, outras maneiras de existir enquanto música. Nesse sentido, a referência do violão europeu de concerto reproduz, no ensino acadêmico, uma estrutura de colonialidade em relação as nossas outras referências musicais. Essa hegemonia, bem como, essa posição colonizadora reafirmam uma estrutura de quadros de opressão oriundos do conhecimento, muitas vezes hegemônico, a violência epistêmica, que podem ser diversas (ARAÚJO, 2006). Essas violências também podem ser vistas como colonialidades do poder, do saber e do ser, como defendem Anibal Quijano, Walter Mignolo e Maldonado-Torres. Nessa perspectiva, o termo colonialidade significa que:

\begin{abstract}
Apesar do fim do colonialismo, "um padrão de poder que emergiu como resultado do colonialismo moderno, porém, ao invés de estar limitado a uma relação formal de poder entre os povos ou nações, refere-se à forma como o trabalho, o conhecimento, a autoridade e as relações intersubjetivas se articulam entre si através do mercado capitalista mundial e da ideia de raça". (MaldonadoTorres, 2007, p. 131). A colonialidade sobrevive até hoje "nos manuais de aprendizagem, nos critérios para os trabalhos acadêmicos, na cultura, no senso comum, na autoimagem dos povos, nas aspirações dos sujeitos, e em tantos outros aspectos de nossa experiência moderna" (idem) (OLIVEIRA, 2017, p. 2).
\end{abstract}

Esta estrutura de colonialidade do saber está presente em grande parte dos cursos de música oferecidos nas universidades brasileiras, o que contribui para o que Pereira (2014) chama de "habitus conservatorial". Estes cursos, em sua maioria, têm pouco, ou nenhum diálogo com os saberes e fazeres ligados às múltiplas referências musicais que constituem a(s) música(s) brasileira(s). Nos cursos de bacharelado em violão, voltados para a formação de violonistas solistas, essa problemática acaba sendo amenizada visto que uma justificativa possível para essa visão é que os cursos se propõem a formar concertistas voltados para este tipo de música, mesmo 
reconhecendo que na prática nem sempre é o que acontece profissionalmente. Nos casos de componentes de violão ligados a outros cursos superiores de música, essa problemática acaba se redimensionando visto que a formação instrumental busca suprir questões que vão além da execução de peças que fazem parte do repertório de concerto tradicional. Nos cursos de formação de professores de música, mais especificamente aqueles que buscam formar profissionais para suprir a demanda das escolas de educação básica do país, muitas vezes, por ser um instrumento de fácil locomoção e de baixo custo, o violão torna-se um dos instrumentos mais utilizados por esses educadores em sala de aula, assumindo diversas funções a depender do interesse e da expertise do educador musical na execução do instrumento. Assim, torna-se fundamental entender que o uso do violão na educação musical tem um caráter específico e que a formação oferecida nos bacharelados, que na maioria das vezes tem o objetivo de formar violonistas solistas para executar música de concerto ${ }^{12}$, não contempla a necessidade do educador musical em sala de aula.

Moura (2008), fez um estudo de caso em turmas da disciplina instrumento suplementar da escola de música da UFBA. E no que tange ao conteúdo trabalhado, a autora opina destacando pontos frágeis que podem ser melhores trabalhados dentro do programa da disciplina. Visando uma maior articulação com as possibilidades futuras de atuação profissional dos licenciandos. A autora diz que:

Talvez, pudesse ser mais trabalhado durante as aulas as músicas populares cifradas, em forma de canção, o que não significa abolir o uso da partitura, mas induzir os estudantes a se desenvolverem em outros aspectos musicais. Por exemplo, acerca da harmonia da MPB, chamar a atenção para outras formas de resoluções harmônicas que não as resoluções da harmonia tradicional (MOURA, 2008, p. 143).

Neste ponto, a autora observa que, respeitando as especificidades da atuação dos alunos que são públicos desta disciplina, existe a necessidade da inclusão de outras formas de pensar o violão que não seja apenas a do violão

\footnotetext{
12 Sobre a formação de violonistas solistas na UFBA, vide: SOUZA, Luan Sodré. Ensino de violão para violonistas solistas em uma classe de seminários em instrumento na graduação. 2015. 96f. Dissertação (Mestrado em Música) - Escola de Música, Universidade Federal da Bahia. 2015.
} 
solista de tradição europeia. De 2008, ano de publicação do trabalho da referida autora, até o ano atual, houveram mudanças. Através de observações assistemáticas nas aulas da Profa. Dra. Cristina Tourinho, pude observar que a canção e o uso de cifras foram incorporados nas aulas. Também tive acesso a relatos de estudantes que afirmaram que esses conteúdos foram incorporados nos seus cursos. Mas percebo que ainda assim impera uma lógica da música ocidental europeia, mesmo quando o repertório se refere a músicas de tradições afro-brasileira. Moura (2008, p. 62), disse que "o professor também inclui[u] uma parcela de músicas populares brasileiras no repertório das disciplinas, o que dá a entender que o estudo do violão já não est[ava] mais centrado em músicas de tradição europeia". Após observar a variedade de elementos que estão ligados a uma concepção de tradição musical, como visto no panorama sobre os Sambas do Recôncavo da Bahia, não concordaria com a autora neste ponto, já que considero que apenas uma mudança no repertório não representa uma alteração na concepção do ensino musical. Como foi visto, há variáveis no que tange a concepção musical, a filosofia, a conceitos, a funções, ou seja, a questões epistemológicas. Mesmo incluindo músicas populares brasileiras no repertório da disciplina, estas precisariam ser vistas epistemologicamente, assim como é feito na música de tradição europeia. Dessa maneira é emergencial a busca de outros caminhos para essa formação musical.

\section{UMA PROPOSTA DECOLONIAL DE ENSINO COMO ALTERNATIVA À COLONIALIDADE DO SABER}

A integração entre o corpo e a música, tão presente no samba de roda, sugere uma visão integrada e ampla da ritualidade do samba, o que de certa forma, nos convida a uma lógica de enxergar o mundo de uma maneira mais ampla, em contraste com a visão fragmentada típica do pensamento moderno científico ocidental europeu, como defende Christopher Small $(1996)^{13}$. A maneira como a ritualidade do samba se relaciona com a temporalidade, como se organiza estruturalmente, a forma que é dada ao

\footnotetext{
${ }^{13}$ Para um maior aprofundamento sobre a relação entre cultura, sociedade, educação e visão de mundo, bem como das diferenças entre a visão cultural e científica ocidental europeia e outras culturas, ver a obra Music, society and education de Christopher Small (1996).
} 
fazer - cíclica, relativa, inesperada - de alguma forma, materializa na roda uma visão de mundo circular, uma temporalidade onde passado, presente e futuro convivem lado a lado, onde o fim é inesperado, portanto focando num presente constante sem fim estabelecido.

Vale ressaltar a importância da memória como um artefato sagrado, mas não só por ser responsável pelo trânsito entre passado e presente, ou como forma de registro dos saberes e fazeres, mas como uma dimensão que materializa a tradição em cada um. Há uma relação de "ser" se opondo a ideia do "ter" presente em outras lógicas culturais. Os saberes e fazeres do samba estão nas pessoas e podem ser acessados por elas a qualquer momento, existe uma fusão entre a tradição e o participante. Nesse caso, o corpo torna-se um arquivo vivo, o lugar onde os saberes são escritos. As pessoas são, independente de ter ou não ter. Como declara Roberto Mendes e Waldomiro Júnior:

A chula ${ }^{14}$ é sempre ritualística. Nela não está inserido apenas canto e dança, melodia e expressão corporal. É também um canto de fé, de reverência às tradições e de saudações ao espírito. Nela está a essência de cada um, a ancestralidade histórica e genética, que somadas formam tudo o que somos hoje, como indivíduo e povo (MENDES; JÚNIOR, 2008, p. 21).

Não poderia falar dos Sambas do Recôncavo sem falar do "portal", do palco, do lugar onde a vida é recriada, do "templo" ou do "terreiro", do local sagrado, da roda. A roda, talvez um dos principais elementos dos sambas de roda - tanto que adjetiva essa manifestação, qualificando, fazendo dela tão roda quanto samba - se materializa através das pessoas que disponibilizam os seus corpos para uma experiência lúdica e expressiva, dispondo-se de maneira circular, represando e circulando o axé15 que é gerado pelo ritual. É o lugar onde de maneira ritualística, a memória, a oralidade, se materializam através do fenômeno acústico que acessa a corporeidade das pessoas, que por sua vez, se conectam com uma temporalidade que também é circular (ABIB, 2004; CANDUSSO, 2009).

\footnotetext{
${ }^{14}$ Neste trabalho entendo a Chula como um tipo de samba de roda, me respaldando nas minha vivência, observação da manifestação e na visão de Doring (2016) e Nobre (2009) . Esta opinião contrasta com a de Roberto Mendes (2008), que considera que a Chula e o samba de roda são manifestações diferentes, inclusive crendo que a Chula é anterior ao samba de roda.

${ }^{15}$ Energia vital.
} 
Como já comentado neste texto, a transmissão do conhecimento no contexto da cultura popular e, consequentemente dos Sambas do Recôncavo, se dá principalmente através da roda. Ela é um lócus de transmissão do conhecimento ancestral, aquele que traz a herança cultural deixada pelos antepassados, saberes que foram armazenados numa memória coletiva, de maneira viva. Tal herança se materializa na própria pessoa através do seu comportamento espiritual, corporal, social, que quando acessados na roda dão vida a uma ritualidade que perpetua um passado que se recria no presente, carregando o respeito aos ancestrais e aos saberes tradicionais do grupo. Essa ritualidade, que é desenvolvida na roda, por um lado pode funcionar como uma espécie de iniciação na qual os mestres transmitem, por meio da oralidade, os saberes de maneira aplicada. Por outro lado, pode ser um acesso, um portal que se abre para o passado, uma lembrança lúdica e coletiva, uma transposição do aqui e do agora para tempos imemoriais, para locais sagrados, onde tudo se originou, um relembrar em conjunto. É onde existe a conexão com o sagrado particular, que é constituído em cada um através da sua experiência de vida (ABIB, 2004). Segundo Abib (2004, p. 69-70), "Não há quem não experimente a sensação de que algo sagrado está realmente acontecendo, no momento em que o berimbau [...] faz soar seus acordes para dar início a uma roda tradicional de capoeira angola." Concordo com o autor, ao mesmo tempo, que poderia utilizar esta mesma afirmação para descrever a sensação que tenho quando uma viola faz a chamada para dar início ao samba de roda. Algo especial acontece neste momento. Falando a partir da minha experiência, é como se o toque da viola funcionasse como uma chave para abrir uma porta que me leva diretamente para um passado em que eu não vivi conscientemente, mas que está registrado em mim. Para os mais espiritualistas, diria que algo de muito espiritual acontece neste momento. Sim, não é possível falar de samba de roda sem falar do espiritual, do sagrado, da devoção, do sobre natural. Isso é samba de roda. Para o autor (ibid, p. 70), "O ritual instaura um mundo paralelo, em relação direta com uma nova cosmogonia que é recriada através das construções simbólicas referentes ao tempo mítico primordial".

Na perspectiva da temporalidade, no samba de roda, no ritual, o tempo não segue uma lógica linear de início, meio e fim; presente, passado e futuro, nestas ordens. Pelo contrário, o passado está materializado no presente, ao mesmo tempo que o futuro está sendo gestado como já fora no 
passado. Essa é uma perspectiva circular da temporalidade. Segundo Abib (2004, p. 74) "o passado não pode ser visto como algo inerte, cristalizado no tempo, algo que foi, mas como algo vivo, que vigora e que tensiona com o presente, abrindo possibilidades futuras". Neste caso, a concepção linear de tempo, característica da lógica de racionalização do sistema-mundo colonial europeu é totalmente modificada, gerando um fenômeno musical que se liga ao passado para fazer um presente constante, sem uma previsão de futuro. Musicalmente, na roda, essa racionalidade pode ser observada e ouvida pela forma como o samba acontece. Ele tem um início no nosso tempo presente, acessa o passado através da sonorização e da corporalização da memória ancestral. No entanto, o futuro não existe, nem em projeto. Não há hora de terminar. O que importa é o agora, o ritual, o presente construindo o futuro e ao mesmo tempo gerando o passado. E assim segue o ciclo através das rodas e das gerações (ABIB, 2004). Toda essa lógica diferenciada de se pensar um fazer que também é musical me faz pensar: será que não há também outros caminhos para pensar e ensinar o violão? E mais, será que estas outras lógicas que estão presentes nos Sambas do Recôncavo Baiano não poderiam também ser estruturantes para pensar um ensino de violão na graduação de um outro lugar? De que maneira essas outras lógicas de se pensar música poderiam contribuir para a construção de um novo conhecimento/saber práticoteórico-musical-violonístico?

Sobre outras maneiras de se pensar o violão e, dessa vez, falando especificamente sobre os Samba do Recôncavo e, mais especificamente ainda, o Samba Chula, Mario Ulloa (2008), fazendo uma análise da maneira peculiar do violonista Roberto Mendes tocar diz que o acompanhamento executado no instrumento é como uma sequência contínua de sons ritmados e entrelaçados, à maneira do pandeiro. Ou seja, segundo o autor, há um pensamento que está ligado a um outro instrumento que compõe a formação instrumental do Samba de Roda. Ele ainda diz que:

\footnotetext{
Na maior parte das vezes, o conjunto "dedos-munheca" atua como um plectro (palheta), e os movimentos daí oriundos acontecem de duas formas. Na primeira forma, o tecido de sons surge da alternância dos dedos polegar e indicador (p-i, p-i, p-i); já na segunda forma, uma variante da primeira, os dedos indicador-médio, não alternam os movimentos entre si, como seria de praxe, eles atuam num bloco só, bem coladinhos, como formando um único dedo (ULLOA, 2008, p. 56).
} 
Buscando ser mais didático, o professor continua dizendo:

Para ajudar na compreensão visual e auditiva desse gesto musical, o leitor pode imaginar um percussionista que toca uma "caixinha de fósforo". Penso que essa ação fixar os dedos p-im para prender e balançar a caixinha com a munheca e o antebraço - é a mais semelhante aos movimentos que Roberto realiza com a sua mão direita (ULLOA, 2008, p. 56).

Trazendo apenas este exemplo, já seria possível inferir que existem outras possibilidades técnicas para se tocar o violão, o que por si só, já relativizaria a técnica acadêmica do violão, caso o samba de roda fosse considerado neste contexto. Esta relativização incluiria posicionamento de mãos, ataque, maneira de sentar, timbre, disposição da mão esquerda no braço do instrumento, maneira de pensar e produzir som. Embora seja possível encontrar movimentos equivalentes na tradição do violão de concerto europeu, como Mário destaca na sua análise, quando relaciona a alternância dos dedos pelegar-indicador com a figueta, da Renascença - o ataque do dedo indicador em direções opostas com a técnica do dedilho - o deslizar do dedo polegar sobre duas ou mais cordas subsequentes, em direção à primeira corda com o deslizamiento ou glissando da mão direita; estas técnicas são utilizadas em contextos específicos. Mario Ulloa (ibidem), afirma que a técnica de mão direita do violonista Roberto Mendes, que é inspirada nos toques de viola machete dos Sambas do Recôncavo Baiano, difere significativamente das práticas que ele conhece. O relato do violeiro e pesquisador Cássio Nobre concorda com a análise de Mario Ulloa, explicitando esta outra maneira de se tocar a viola, que foi herdada pelos violonistas que têm os Sambas do Recôncavo Baiano como referência:

A técnica empregada pelos violeiros dos sambas do Recôncavo é considerada por músicos profissionais como sendo bastante "rica" e, ao mesmo tempo, "simples" e "complexa". O chamado "toque", ou "pinicado", ou "ponteio" da viola nos sambas do Recôncavo Baiano consiste em uma série de combinações de movimentos com as mãos, geralmente executados exclusivamente pelos dedos indicador e polegar, executando-os "melodicamente" ou combinando "harmonicamente" os pares de cordas que estão sendo tocados. Raramente se utilizam outros dedos para ferir as cordas da viola. O que mais caracteriza a técnica deste instrumento nesta região é mesmo o que muitos violeiros e sambadores chamam "pinicado". Esta técnica confere um efeito sonoro único à 
prática dos sambas no Recôncavo, principalmente devido à disposição de pares de cordas oitavados na viola. Enquanto o polegar fere a corda mais aguda, por estar mais acima no instrumento, o indicador fere a corda mais grave, que está logo abaixo[...] (NOBRE, 2008, p. 102).

Músicos com vivência nos Sambas do Recôncavo, como Roberto Mendes, Raimundo Sodré, Gilberto Gil, Paulinho Dafilin, Jurandir Santana, Munir Hossn, Alex Mesquita, Marcos Bezerra, Gerson Silva, Raymundo Nova, dentre outros, conseguiram transpor para o violão e para a guitarra esta maneira peculiar de tocar, conseguindo resultados sonoros interessantes a partir da ressignificação dessa maneira de tocar a viola transportada para o violão e a guitarra.

Embora - conforme exposto por Cássio Nobre - várias sintaxes musicais do Recôncavo estejam sendo transpostas a outros instrumentos e aportando na música urbana de Salvador é através do violão que ela se materializa de forma mais homogênea e presente, provavelmente pela representatividade do instrumento no campo da música popular brasileira e por também reconhecida característica de transito fluido na sociedade e de sintetizar novidades idiomáticas, aqui, fortemente inclinadas ao plano percussivo - ou das "cordas feridas" como expôs Roberto Mendes (p.150). Através deste protagonismo, o violão acaba servindo como elemento de coesão que firma uma indissociação e calcifica Salvador e seu Recôncavo como um único "módulo" cultural/musical, que, embora tenha nas setas de sua linha de continuidade imaginária (histórica) apontamentos diametralmente opostos (passado/ futurorural/urbano) representa - para os nativos - a própria síntese de sua identidade que é imantada no trânsito entre estas extremidades (REA, 2014, p. 154).

Como diz Cássio Nobre, em entrevista a Adriano Rea (2014, p. 117), "o que Roberto (Mendes) faz não é chula, se ele for lá pra São Félix e tocar com um violeiro de lá o cara não vai dizer que é, já é uma outra coisa". Creio que essas outras coisas, podem ser pontes de construção de conhecimento, a partir do encontro epistemológico musical. Essa outra "coisa", ao meu ver, representa a ideia de um conhecimento fronteiriço. Assim creio que "outras coisas" podem ser construídas em todo um âmbito do ensinar e aprender música no Brasil. Desta forma, me pergunto: seria possível que o ensino nas turmas de violão também dialogasse epistêmicamente com os Sambas do Recôncavo Baiano gerando “outras coisas”, outros conhecimentos? 
No que tange, especificamente ao ensino de violão, encontrei poucos trabalhos que se relacionam diretamente com esta temática. No entanto, é fundamental citar o trabalho do Robson Barreto Matos (2009), que traz o choro brasileiro para o contexto do ensino da técnica violonística, apontando caminhos alternativos para se ensinar violão no contexto acadêmico, bem como uma tentativa de se relacionar com as tradições musicais brasileiras em uma camada além do repertório. Outro trabalho importante para esta discussão é o de Alex Mesquita (2012), que faz uma catalogação de elementos musicais idiomáticos para o violão e a guitarra no contexto dos Sambas do Recôncavo Baiano. Em um outro viés, Adriano Maraucci Rea (2014) - sem se referir especificamente ao ensino, mas trazendo uma discussão que poderia dar suporte a uma iniciativa de ensino - fez uma pesquisa etnográfica, na qual ele buscou defender o conceito de um violão baiano. Para tal, ele analisou musicalidades, identidades e concepções musicais, presentes na execução e nos discursos de músicos/violonistas baianos que se relacionam diretamente com a música popular feita na Bahia. Sobre sua busca, ele concluiu que

[...] o violão baiano é um termo e uma concepção instrumental em franca construção e sua estabilidade depende do Recôncavo. Ele ocorre em Salvador, em uma acepção de música e postura "moderna", mas alimenta-se da sua porção "interiorana", na originalidade da ancestralidade, mais uma vez expondo a friç̧ão constitutiva da $\mathrm{Ba}(\mathrm{h}) \mathrm{ia}$. Em alguns momentos, ele aparece na fala nativa, em outros, é negado, porém sua existência parece inquestionável (REA, 2014, p. 153-154).

A meu ver, o conceito defendido pelo autor é mais uma "outra coisa" fruto das dinâmicas de interação fronteiriça nos campos dos conhecimentos / saberes musicais. Ele continua dizendo:

Assim, este violão baiano representa, no campo idiomático/sintático do violão brasileiro, uma identidade e concepção própria e destacada regionalmente das demais; alinha uma "continuidade musical" funcionando como aliança entre a construção do futuro e do passado e por consequência, acaba por consumar e definir, através das musicalidades articuladas, os prismas possíveis e desejáveis de uma identidade local reclamada pelos nativos deste estudo (REA, 2014, p. 154-155).

Creio que estas pesquisas têm um papel político fundamental para se repensar epistemologicamente o violão acadêmico brasileiro. São trabalhos 
pioneiros e que abrem todo um campo de discussão fundamental, no que tange ao ensino acadêmico do violão na contemporaneidade, inaugurando caminhos de diálogos epistemológicos, teóricos e práticos na formação violonística brasileira e baiana.

É nesse contexto que defendo uma proposta decolonial de ensino em resposta a essa colonialidade do saber musical e violonístico, norteada por um pensamento crítico de fronteira constituído a partir da inserção dos saberes e fazeres dos Sambas do Recôncavo Baiano nas aulas coletivas de violão na graduação. Para tal, considerando alguns pressupostos como, por exemplo, as ideias de Donna Haraway (1995), em relação a um determinado conceito de "objetividade" semeado nas pesquisas científicas e a caminhada em direção a apresentação de uma alternativa para o relativismo e para a totalização dos saberes através da ideia de saberes localizados, os quais são parciais, localizáveis e críticos. Em outra perspectiva, a ideias de bell hooks (1995), sobre o papel político, identitário e de resistência que as artes representaram e ainda representam para o povo negro norte-americano. Ainda neste campo acho importante considerar o trabalho de Milton Santos (1977), que à luz das teorias marxistas, também contribui para pensar a construção da ideia de "espaço" na sociedade e argumenta em defesa da importância do espaço e das formas, defendendo a ideia de formações socioespaciais e a territorialidade. Segato (2007), também reflete sobre a noção de espaço, território e lugar, ampliando os conceitos e passando por diversas áreas, como política, geografia, cultura, religião, pesquisa, sociologia e culmina levantando a ideia do pertencimento que reflete na construção das identidades e nas delimitações de áreas de estudo. No ensino de violão, discussões como essas nos remete a pensar sobre os lugares, territórios e espaços no campo da música, assim influenciando nos repertórios que levamos para a sala de aula, nos valores e concepções de cada música, nas abordagens das técnicas, nas maneiras de pensar o instrumento, na forma de fazer música, e no que consideramos como música. O que proponho é um giro decolonial nesse campo do ensino musical. Um exercício de pensar de um outro lugar, mais especificamente, pensar a partir da fronteira entre duas referências musicais importantes na formação do educador musical, da cultura popular local - aqui representada pelos Sambas do Recôncavo - e os saberes acadêmicos tradicionais. Por outro viés, não se pode perder de vista que conhecimento é poder e, se a pesquisa é uma forma de construir 
conhecimento, ela também é uma maneira de empoderamento. Assim, essa busca é também um ato político em direção de uma sociedade que realmente considere a sua diversidade de maneira não subalternizada. Para Rubem Alves,

\begin{abstract}
Ao produzir uma pesquisa, portanto, naõ estou produzindo um conhecimento puro, solto no ar, conhecimento que ira simplesmente tornar os homens mais sabios. Estou produzindo poder e este poder ira ser usado por alguem. [...] todo ato de pesquisa e um ato politico. O conhecimento que produzo sera usado por alguem num projeto especifico de controle $\mathrm{e}$ manipulac a ã. Na medida em que o pesquisador se engana a si mesmo, pretendendo estar produzindo conhecimento puro, ele se presta a ser manipulado mais doćil e ingenuamente. (1980, p. 73)
\end{abstract}

Assim essa busca é fruto de uma militância em prol de uma educação musical brasileira e que reflita os valores e processos formativos da(s) música(s) do(s) povo(s) brasileiro(s), também visa contribuir no estreitamento das relações entre os diversos saberes, os da academia e os da cultura popular. Essa proposta acredita que o entre-lugar é parte da identidade do povo brasileiro e, não deveria ser diferente no ensino de música.

Essa ideia do pensamento de fronteira, que é uma tentativa de interação com a modernidade colonial a partir da perspectiva dos sujeitos subalternizados, ao contrário de uma negação das contribuições do sistemamundo europeu, e no caso da discussão desta pesquisa, da música europeia de concerto e do ensino de violão eurocentrado, propõe uma visibilização de epistemologias historicamente subalternizadas, com o objetivo de criar um local de construção de conhecimentos de fronteira. Na perspectiva do projeto decolonial, as fronteiras não são somente este espaço onde as diferenças são reinventadas, são também o local onde são formulados conhecimentos a partir das perspectivas, cosmovisões ou experiências dos sujeitos subalternizados. O que estaria implícito nessa afirmação é uma conexão entre o lugar e o pensamento.

O pensamento de fronteira não é um pensamento fundamentalista ou essencialista daqueles que estão à margem ou na fronteira da modernidade. Justamente por estar na fronteira, esse pensamento está em diálogo com a modernidade, porém a partir das perspectivas subalternas. Em outras palavras, o pensamento de 

projeto eurocêntrico da modernidade (BERNARDINOCOSTA; GROSFOGUEL, 2016, p. 18-19).

Assim, o que proponho neste trabalho é a possibilidade de construção de um conhecimento decolonial, por não ser hegemônico, por ser localizado, por ter uma referência historicamente subalternizada em diálogo com uma referência hegemônica a fim da construir um conhecimento de fronteira, não hegemônico e dialógico, situado e contextualizado identitariamente. De forma alguma, busca-se uma imposição dos Sambas do Recôncavo como a nova referência hegemônica acadêmica, pelo contrário, os Sambas do Recôncavo Baiano são vistos, aqui, como possibilidades/exemplo de uma outra referência não acadêmica, historicamente subalternizada e que permite possibilidades de diálogo para a construção de um novo conhecimento músico-educacional no ensino de violão. Esse trabalho milita por uma ecologia de saberes e defende o diálogo acadêmico com as diferentes referencias musicais brasileiras, respeitando principalmente as identidades, os saberes localizados e tendo o diálogo no campo dos saberes como uma ação de luta contra a violência epistêmica que tem sido tônica no projeto acadêmico brasileiro vigente até então. E, além disso, encoraja iniciativas de diálogos epistêmicos a partir de outras tradições brasileiras.

\section{Umbigada $^{16}$}

Vejo essa discussão, bem como a construção dessa proposta de fronteira como um grande desafio, no entanto acredito que é extremamente necessário para que as culturas brasileiras possam estar presentes também dentro das universidades de maneira consistente, a fim de compor a formação musical e humana dos profissionais. Assim, fazendo com que a universidade dialogue consistentemente com a diversidade de identidades do povo brasileiro, tornando-se um espaço de formação realmente amplo, democrático, diverso. Além disso, possibilitando uma formação em diálogo com a comunidade de maneira geral, por meio do intercâmbio de conhecimentos de maneira horizontal, mas acima de tudo, construindo lentes descolonizadas para enxergar o mundo. Uma reflexão do ensino de música

${ }^{16}$ Umbigada é o termo utilizado para nomear o momento em que a sambadeira termina de sambar na roda e convida a próxima sambadeira a entrar na brincadeira. É como um rito de passagem. 
numa dimensão superficial, sem tratar dos valores inerentes a cada tradição, muitas vezes a partir de aspectos ligados a outras músicas, incorre no risco de contribuir para a propagação de conceitos equivocados e preconceituosos. É preciso um olhar epistemológico. Esse tipo de atitude contribui para o respeito e valorização dos saberes não canônicos, para uma justiça cognitiva e consequentemente social ${ }^{17}$. Uma educação musical que considere os saberes localizados $^{18}$, contribui para uma visão ampla de diversidade, trazendo fundamentos para a busca de etnofilosofias, de heteroglossias, de desconstruções e de conhecimentos locais, ao mesmo tempo, entendendo que dentre outras questões, saberes localizados refletem resistência, empoderamento, força política e identidade. E assim, contribui para uma ecologia de saberes onde cada saber tem o seu valor respeitado.

\section{Referências}

ABIB, Pedro Rodolpho Jungers. Capoeira Angola: cultura popular e o jogo dos saberes na roda. Campinas: CMU publicações. Salvador: EDUFBA, 2005.

ABIB, Pedro Rodolpho Jungers. Capoeira Angola: cultura popular e o jogo dos saberes na roda. Tese (Doutorado em Ciências Sociais Aplicadas à Educação), UNICAMP, 2004.

ALMEIDA, Cristiane. M. G. Por uma ecologia da formação de professores de música: diversidade e formação na perspectiva de licenciandos de universidades federais do Rio Grande do Sul. Tese (Doutorado em Música) Instituto de Artes, Universidade Federal do Rio Grande do Sul, Porto Alegre, 2009.

ALVES, Rubem. Conversas com quem gosta de ensinar. São Paulo, Editora Cortez, 1980.

ARAÚJO, Samuel. A violência como conceito na pesquisa musical: reflexões sobre uma experiência dialógica na Maré, Rio de Janeiro. Trans. Revista Transcultural de Música, n. 10, diciembre, 2006.

BARRETO, Luciana; ROSÁRIO, Rosildo; GUMES; Scheilla (Org.). Mulheres do Samba de Roda. Projeto Mulheres do Samba de Roda: Santo Amaro, 2015.

\footnotetext{
17 Para uma visão mais aprofundada sobre e valorização dos saberes não ocidentais, justiça cognitiva, justiça social e ecologia dos saberes, ver Boaventura de Sousa Santos (2007).

${ }^{18}$ Para uma discussão mais aprofundada sobre saberes localizados, ver Donna Haraway (1995).
} 
BERNARDINO-COSTA, Joaze; GROSFOGUEL, Ramón. Decolonialidade e perspectiva negra. Revista Sociedade e Estado - v. 31, N. 1 Janeiro/Abril, 2016.

BERTISSOLO, Guilherme. Composição e capoeira: dinâmicas do compor entre música e Movimento. Tese (Doutorado). Universidade Federal da Bahia. Escola de Música, 2013.

BIANCARDI, Emília. Raízes Musicais da Bahia. Salvador: Osmar G, 2000.

BRAGA, Simone; TOURINHO, Cristina. Um por todos ou todos por um. processos avaliativos em música. Feira de Santana: UEFS Editora, 2013.

CANDUSSO, Flavia. Capoeira Angola, educação musical e valores civilizatórios afro-brasileiros. Tese (doutorado) - Universidade Federal da Bahia. Escola de Música, 2009.

CARMO, Raiana Alves Maciel Leal do. A política de salvaguarda do patrimônio imaterial e os seus impactos no samba de roda do Recôncavo baiano. Dissertação (Mestrado em Música). Universidade Federal da Bahia, Escola de Música, 2009.

DÖRING, Katharina. Cantador de Chula: o samba antigo .... Serie sons da Bahia. Salvador: Pinaúna Editora, 2016a.

DÖRING, Katharina. A Cartilha do Samba Chula. Salvador: Umbigada, 2016b.

DUSSEL, Enrique. Transmodernidade e interculturalidade: interpretação a partir da filosofia da libertação Revista Sociedade e Estado - Volume 31 Número 1, Janeiro/Abril, 2016.

EXDELL, Charles. Violeiro de samba: retratos do samba de roda no Sertão Baiano. Dissertação (Mestrado em Música). Universidade Federal da Bahia, Escola de Música, 2017.

PEREIRA, Marcus Vinícius Medeiros. Licenciatura em música e habitus conservatorial: analisando o currículo. Revista da ABEM, Londrina, v. 22, n. 32, p. 90-103, jan.jun, 2014.

GALILEIA, Carlos. Violão Ibérico. Rio de Janeiro: Trem Mineiro Produções Artísticas, 2012.

GRAEFF, Nina. Os Ritmos da roda: Tradição e transformação no samba de roda. Salvador: EDUFBA, 2015.

GROSFOGUEL, Ramón. Para descolonizar os estudos de economia política e os estudos pós-coloniais: transmodernidade, pensamento de fronteira e colonialidade global. In: SANTOS, Boaventura de Sousa; MENESES, Maria 
Paula (Org.). Epistemologias do Sul. Coimbra: Edições Almedina. p. 383-417, 2009.

HARAWAY, Donna. Saberes Localizados: a questão da ciência para o feminismo e o privilégio da perspectiva parcial. Cadernos Pagu (5), p.07-41. Disponível em: <http://periodicos.bc.unicamp.br/ojs/index.php/cadpagu/article/view/1773> . Acessado em: 02/07/2008, 1995.

hooks, bell. An Aesthetic of Blackness: Strange and Oppositional, In: Lenox Avenue: A Journal of InterEarts Inquiry, vol. 1, pp. 65E72, 1995.

KRAEMER, Rudolf-Dieter. Dimensões e funções do conhecimento pedagógicomusical. Trad. Jusamara Souza. Em Pauta, v. 11, n. 16/17, p. 49-73, abr./nov., 2000.

KUBIK, Gerhard. Angolan Traits in Black Music, Games and Dances of Brazil. Lisboa: Junta de Investigações do Ultramar, 1979.

LORDELO, Petry Rocha. O samba chula de cor e salteado em São Francisco do Conde/ BA: cultura populá e educação não-escolá para além da(o) capitá. $198 \mathrm{f}$. Diseertação (Mestrado) - Departamento de Educação, Universidade Federal da Bahia, Salvador, 2009.

MATOS, Robson Barreto. Choro:uma proposta de ensino da técnica violonística. 248 p. Tese (Doutorado em música). Escola de Musical, Universidade Federal da Bahia, Salvador, 2009.

MENDES, Roberto; JÚNIOR, Waldomiro. Chula: Comportamento traduzido em canção. Salvador: Fundação ADM, 2008.

MESQUITA COSTA, Alex Augusto. Recôncavo baiano: catalogação de elementos musicais idiomáticos para o ensino de violão e guitarra. Dissertação (Mestrado em Educação Musical). Universidade Federal da Bahia, Escola de Música, 2012, $337 \mathrm{fl}$.

MOURA, Risaelma. J. A. Fatores que influenciam o desenvolvimento musical de alunos da disciplina Instrumento Suplementar (violão). Dissertação (Mestrado em Música) - Escola de Música, Universidade Federal da Bahia. 2008, $152 f$.

MIGNOLO, Walter D. Local Histories/ Global designs: Coloniality, Subaltern Knowledges, and Border Thinking. New Jersey: Princeton University, 1999.

NKETIA, Joseph. H. K. The Music of Africa. Nova Iorque: W. W. Norton \& Company, 1974. 
NOBRE, Cássio. A viola machete no Samba Chula. In: DÖRING, Katharina. A cartilha do Samba Chula. Salvador: Umbigada, 2016, p. 27-29.

NOBRE, Cássio. Samba chula enquanto world music: políticas públicas e produção fonográfica no samba de roda do Recôncavo Baiano. Tese (Doutorado em Música). Universidade Federal da Bahia, Escola de Música, 2017.

NOBRE, Cássio. Viola nos sambas do Recôncavo baiano. Dissertação (Mestrado música). Universidade Federal da Bahia, Escola de Música, 2008.

OLIVEIRA, Luiz Fernandes. O que é uma educação decolonial? Disponível em: <https://www.academia.edu/23089659/O_QUE_\%C3\%89_UMA_EDUCA\%C3 \%87\%C3\%830_DECOLONIAL> Acessado em: 13 de fev. 2017.

OLIVEIRA, Marcelo Mateus. A improvisação Musical como Ferramenta Pedagógica no Ensino de Violão. Curitiba: Editora Prismas, 2015.

PEREIRA, Marcus Vinícius Medeiros. Licenciatura em música e habitus conservatorial: analisando o currículo. Revista da ABEM, Londrina, v.22, n.32, p. 90-103, jan.jun., 2014.

PINTO, isEpTiago de Oliveira. Som e música. Sonora. Revista de Antropologia, São Paulo, USP, v. 44, n. 1, 2001.

REA, Adriano Maraucci. "Em Busca de um violão baiano" sobre musicalidades, identidades e concepções musicais. Dissertação (Mestrado em Música) Escola de Música, Universidade Federal da Bahia, 2014.

SANDRONI, Carlos. Questões sobre o dossiê do samba de roda. Registro e Políticas de salvaguarda para as Culturas Populares, Rio de Janeiro, Iphan, "Série Encontros e Estudos", n.6, p.45-53, 2005.

SANDRONI, Carlos; PIRES, Josias (Org.). Samba de roda, patrimônio da humanidade. (CD com livreto). Salvador: Amafro, 2006.

SANDRONI, Carlos.; SANT'ANNA, Marcia (Org.). Samba de roda no Recôncavo baiano. Brasília: Iphan, 2007.

SANDRONI, Carlos. Samba de roda, patrimônio imaterial da humanidade. Revista Estudos Avançados. n. 24, vol. 69, p. 373-388, 2010.

SANTOS, Milton. Sociedade e Espaço: Formação Espacial como Teoria e como Método. IN: SANTOS, Milton. Espaço e sociedade: Ensaios. 2a ed. Petrópolis: Vozes, 1982. 
SEGATO, Rita Laura. En busca de un léxico para teorizar la experiencia territorial contemporánea. In: SEGATO, Rita Laura. La nación y sus otros. raza, etnicidad y diversidad religiosa en tiempos de políticas de La identidad. Buenos Aires: Prometeo, 2007.

SMALL, Christopher. Music, Society and Education. Hanover: Wesleyan University Press. 1996.

SOUSA SANTOS, Boaventura de. Para além do Pensamento Abissal: das linhas globais a uma ecologia de saberes. Revista crítica de Ciências Sociais, Coimbra, n. 78 , p. 3-46, out., 2007.

SANTOS, B. S.; MENESES, M. P. (Org.). Epistemologias do Sul. São Paulo: Cortez, 2009.

SOUZA, Luan Sodré. Ensino de violão para violonistas solistas em uma classe de seminários em instrumento na graduação. 96f. Dissertação (Mestrado em Música) - Escola de Música, Universidade Federal da Bahia, 2015.

ULLOA, Mario. (Umas) Chulas de Roberto Mendes: Técnicas da mão direita. In: MENDES, Roberto; JÚNIOR, Waldomiro. Chula: Comportamento traduzido em canção. Salvador: Fundação ADM, 2008.

WADDEY, Ralph. Viola de samba and samba de viola in the Recôncavo of Bahia (Brazil). Latin-American Music Review, v.1, n.2, p.196-212, 1980.

WADDEY, Ralph. Viola de samba and samba de viola in the Recôncavo of Bahia (Brazil), Part II. Latin-American Music Review, v.2, n.2, p.252-79, 1981.

WADDEY, Ralph. Viola de samba e samba de viola no Recôncavo baiano. In: SANDRONI, C.; SANT'ANNA, M. (Org.) Samba de roda no Recôncavo baiano. Brasília: Iphan, 2007.

WESTERMANN, Bruno. As coisas e o ensino de violão: Relação entre tecnologias digitais e características do ensino do instrumento no contexto da educação a distância. Tese (Doutorado) - Escola de Música, Programa de PósGraduação em Música, Universidade Federal da Bahia, Salvador, 2017.

ZORZAL, Ricieri Carlini. Explorando master-classes de violão em festivais de música: um estudo multi-casos sobre estratégias de ensino. 2010. 223f. Tese (Doutorado em Música) - Escola de Música, Universidade Federal da Bahia, Salvador, 2010.

Recebido em: 31/10/2018

Aprovado em: 04/12/2018 